\title{
Defining the Cause of Post-Operative Hyponatremia in the Orthopedic Patient
}

\section{Eileen Hennrikus', Andrew Georgeson', Kenneth Leymeister ${ }^{2}$, Simon Mucha1, Brian McGillen1, Ronald Miller1}

${ }^{1}$ Department of Internal Medicine, Pennsylvania State University College of Medicine, Hershey, PA, USA

${ }^{2}$ Department of Orthopedic and Rehabilitation, Pennsylvania State University College of Medicine, Hershey, PA, USA

Email: ehennrikus@hmc.psu.edu

How to cite this paper: Hennrikus, E., Georgeson, A., Leymeister, K., Mucha, S., McGillen, B. and Miller, R. (2016) Defining the Cause of Post-Operative Hyponatremia in the Orthopedic Patient. International Journal of Clinical Medicine, 7, 668-674. http://dx.doi.org/10.4236/ijcm.2016.710072

Received: August 11, 2016

Accepted: October 18, 2016

Published: October 21, 2016

Copyright $\odot 2016$ by authors and Scientific Research Publishing Inc. This work is licensed under the Creative Commons Attribution International License (CC BY 4.0).

http://creativecommons.org/licenses/by/4.0/

\section{Abstract}

Background: Post-operative hyponatremia occurs after 30\% of orthopedic surgeries, increasing morbidity, mortality and hospital length of stays and hospital costs. The cause of the hyponatremia can be varied, hard to diagnose and impact management. The goal of this study was to determine the causes of post-operative orthopedic hyponatremia and to evaluate the accuracy with which nephrologists and internists interpret the data. Methods: This was a retrospective chart review of patients $>21$ years old on the adult total joint service who developed postoperative hyponatremia. A hyponatremic order set was developed and patient fluid status was charted by the presence or absence of edema in non-surgical extremities. The patients were treated by their managing physicians. After one year, data on 51 patients were assembled and sent to three nephrologists and three internists to analyze and diagnose the etiology of the hyponatremia. Results: The most common causes of post-operative hyponatremia were hypovolemia (33.7\%), the syndrome of inappropriate antidiuretic hormone, SIADH (32.4\%), hypotonic fluid (8.2\%), acute kidney injury (5.2\%) and medications $(5.9 \%)$. The interrater agreement, measured by kappa coefficient, was moderate $(0.43 ; 95 \%$ CI $0.34,0.53)$ for the nephrologists and fair $(0.38 ; 95 \%$ CI 0.30 , $0.46)$ for the internists. Conclusions: The majority of post-operative hyponatremia following total joint surgery in adults is from hypovolemia and SIADH. The treatment for these is very different: the first requires fluid resuscitation and the latter, free water restriction. Due to an interplay of peri-operative factors, the diagnosis can be difficult for both internists as well as nephrologists.

\section{Keywords}

Hyponatremia, Internists, Nephrologists, Hypovolemia, SIADH 


\section{Introduction}

In a prior study, we found in our institution a 30\% prevalence of post-operative orthopedic hyponatremia. Post-operative hyponatremia in the orthopedic patient is associated with longer hospitalizations, greater hospital costs, more frequent discharges to extended-care facilities [1] and higher mortality [2]. Identifying the cause and providing appropriate treatment can mitigate the adverse effects of hyponatremia [2]. Hypotonic fluid resuscitation, hypovolemia, medications, comorbidities and acute kidney injury can all cause hyponatremia in the post-operative state. Surgery can also produce non-osmotic stimuli for arginine vasopressin (AVP) release, resulting in the syndrome of inappropriate antidiuretic hormone (SIADH) [3]. Depending on the underlying cause, the treatment of hyponatremia can be markedly different.

However, due to the simultaneous interplay of multiple post-operative factors, diagnosing the cause of hyponatremia can be difficult [4]. In this study, three nephrologists and three internists individually diagnosed the cause of hyponatremia by retrospectively evaluating patient data obtained from a standard hyponatremia algorithm. Frequency of hyponatremia etiologic diagnoses and physician interrater agreement were then assessed.

\section{Methods}

\subsection{Setting and Participants}

A hyponatremia order set was developed for the hospital electronic medical record (EMR). After receiving IRB approval, the adult total joint orthopedic physician assistant was instructed to use this order set on all patients who developed hyponatremia post-operatively. He was also instructed to document in the EMR if the patient had edema of a non-operative lower extremity. The results of these findings were used at the discretion of the medical teams caring for the patients.

Inclusion criteria included: patient $\geq 21$ years old, hospital admission to the total joint surgical service, normonatremia (serum sodium $(\mathrm{Na}) \geq 135$ ) at presentation and hyponatremia (serum $\mathrm{Na}<135$ ) [5] post-operatively. $\mathrm{Na}$ level was corrected for hyperglycemia using the formula: measured $\mathrm{Na}+2.4 \times($ glucose $\mathrm{mg} / \mathrm{dL}-100) / 100$.

Demographic, lab, medication, comorbidity and clinical data were compiled for each patient. A de-identified spreadsheet was sent to three nephrologists and three internists to review. Each physician used the data to determine the etiology of each patient's hyponatremia.

\subsection{Data Collection}

Demographics: age, gender, type of surgery, preoperative (pre-op) date, surgical date and postoperative (post-op) day of first hyponatremia.

\section{Physical exam:}

Pre-op and post-op: blood pressure and pulse,

Post-op edema in a non-operative lower extremity.

\section{Laboratory:}


Pre-op: Serum: sodium (Na), potassium, chloride, bicarbonate, blood urea nitrogen (BUN), creatinine ( $\mathrm{Cr})$, glomerular filtration rate (GFR), glucose, hemoglobin (Hgb), hematocrit (Hct).

Post-op: Serum: Na, potassium, chloride, bicarbonate, BUN, Cr, GFR, glucose, osmolality, uric acid, Hgb, Hct.

Urine: $\mathrm{Na}, \mathrm{Cr}$, urea, osmolality.

Calculated: fractional excretion of $\mathrm{Na}(\mathrm{FeNa})$ and fractional excretion of urea ( $\mathrm{FeUr}$ ).

At the discretion of the managing physicians: thyroid stimulating hormone, cortisol.

Medications: thiazides, selective serotonin reuptake inhibitors (SSRI), nonsteroidal anti-inflammatory drugs (NSAID), angiotensin converting enzyme inhibitors (ACEI), angiotensin receptor blockers (ARB).

Co-morbidities: hypertension, atrial fibrillation, coronary artery disease, congestive heart failure, cirrhosis, renal failure, hypothyroidism, diabetes, adrenal insufficiency.

\subsection{Outcomes}

The primary outcome was the percentage of total diagnosed etiologies for post-operative hyponatremia. The secondary outcome was the diagnostic overall agreement and interrater agreement between the three nephrologists and the three internists.

\subsection{Analysis}

All variables were summarized prior to analysis using frequencies and percentages or means, medians, and standard deviations. All analyses were performed using SAS 9.4 (SAS Institute, Cary, NC). The mean change from pre-op to post-op in sodium, hemoglobin and hematocrit was tested using a paired t-test.

The prevalence of the etiologies of hyponatremia was determined by calculating the percent each diagnosis was named by all six evaluators.

The overall agreement of the six evaluators, the three nephrologists and three internists and the interrater agreement between each pair of evaluators were assessed using the weighted Cohen's kappa coefficient.

\section{Results}

Over the course of twelve months, fifty-one patients on the total joint service developed post-operative hyponatremia. A summary of the patients' demographic and clinical characteristics are outlined in Table 1.

\section{Serum Changes}

The patients had a statistically significant decrease in serum sodium from the preoperative serum sodium levels $(138.5 \pm 3.3)$ compared to the post-operative sodium (131.1 $\pm 2.3, P<0.001)$. Seventy-eight percent of hyponatremia occurred within one day after surgery. Hemoglobin $(12.7 \pm 2.3$ vs. $9.5 \pm 1.8, P<0.001)$ and hematocrit (38.1 \pm 6.1 vs. $28.6 \pm 5.1, P<0.001)$ decreased significantly postoperatively.

Etiology: Figure 1

Hypovolemia $33.7 \%(\mathrm{~N}=103)$ and SIADH $32.4 \%(\mathrm{~N}=99)$ were diagnosed most 
Table 1. Demographic and clinical characteristics.

\begin{tabular}{|c|c|c|}
\hline Variable & $(\mathrm{N}=51)$ & Percentage $\%$ \\
\hline Age (years) & 68.3 & $\mathrm{SD}=13.0$ \\
\hline Female & 32 & 62.8 \\
\hline \multicolumn{3}{|l|}{ Co-Morbidities } \\
\hline Diabetes & 14 & 27.5 \\
\hline Hypertension & 36 & 70.6 \\
\hline Heart Disease & 14 & 27.5 \\
\hline Hypothyroid & 10 & 19.6 \\
\hline Renal Failure & 3 & 5.9 \\
\hline \multicolumn{3}{|l|}{ Medications } \\
\hline Thiazide & 10 & 19.6 \\
\hline SSRI & 8 & 15.7 \\
\hline NSAID & 27 & 52.9 \\
\hline ACEI/ARB & 23 & 45.1 \\
\hline \multicolumn{3}{|l|}{ Procedure } \\
\hline Total Knee Arthroplasty & 17 & 33.3 \\
\hline Total Hip Arthroplasty & 20 & 39.2 \\
\hline Irrigation/Debridement & 7 & 13.7 \\
\hline Other & 7 & 13.7 \\
\hline Elective Surgery & 29 & 57.0 \\
\hline Emergent Surgery & 22 & 43.0 \\
\hline
\end{tabular}

$\mathrm{SD}=$ standard deviation. Heart Disease = coronary artery disease, heart failure, or atrial fibrillation; SSRI = selective serotonin reuptake inhibitors, NSAID—nonsteroidal anti-inflammatory drugs; ACEI-angiotensin converting enzyme inhibitors, $\mathrm{ARB}=$ angiotensin receptor blocker; Other = nail fixation, shoulder arthroplasty, ankle open reduction and internal fixation.

frequently. The other categories included: hypotonic fluid 8.2\% $(\mathrm{N}=25)$, acute kidney injury 5.2\% $(\mathrm{N}=16)$, medications $5.9 \%(\mathrm{~N}=18)$ and undetermined $14.7 \%(\mathrm{~N}=45)$.

Agreement: Table 2

The three nephrologists agreed on the same etiology $43.1 \%(\mathrm{~N}=22)$ of the time with a moderate overall interrater agreement, kappa $=0.43(95 \%$ CI 0.34, 0.53).

The three internists agreed $35.3 \%(\mathrm{~N}=18)$ of the time with a fair overall interrater agreement, kappa $=0.38$ (95\% CI 0.30, 0.46).

Overall agreement between all the doctors was fair, kappa $=0.39$ (95\% CI 0.35, 0.42).

\section{Discussion}

Diagnosing the underlying mechanism of postoperative hyponatremia is difficult. Multiple 


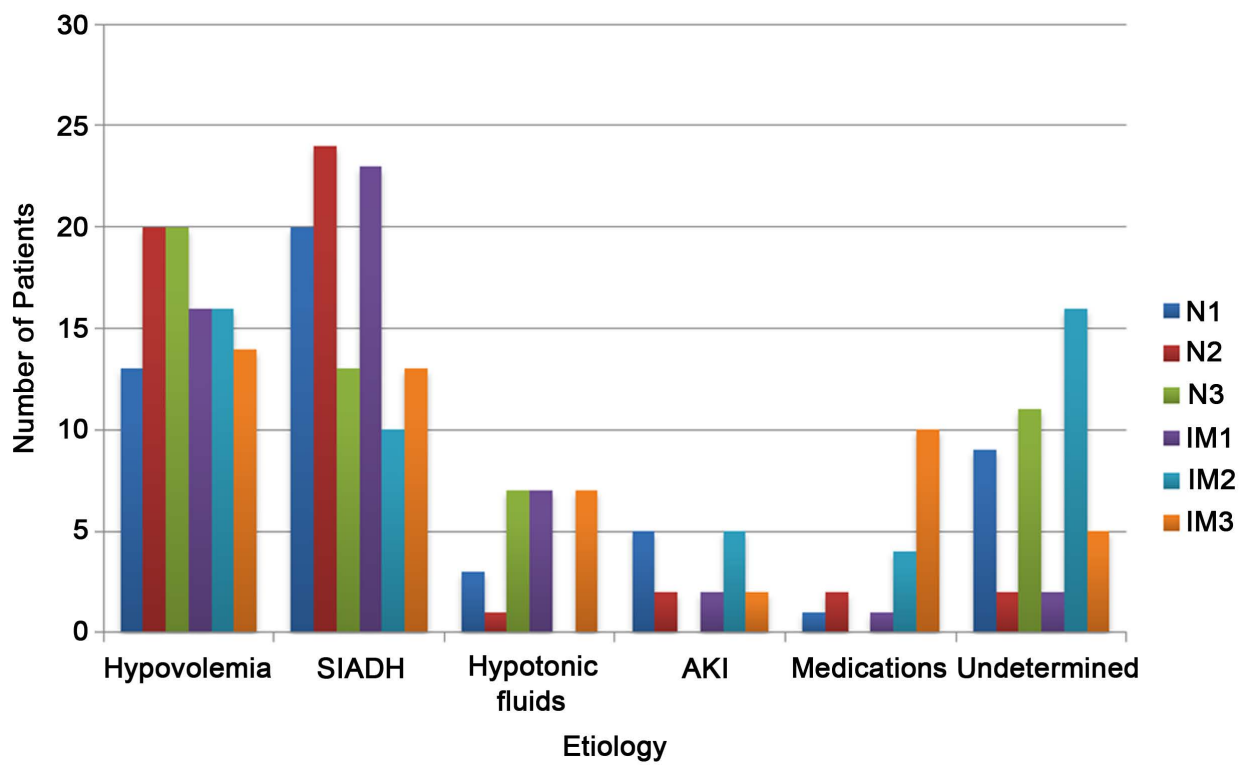

Figure 1. Etiologic diagnoses of post-operative hyponatremia determined by nephrologists and internists. Etiology of post-operative hyponatremia per three nephrologists $(\mathrm{N})$ and three internists (IM). Key: $\mathrm{N}_{1}=$ nephrologist $1 ; \mathrm{N}_{2}=$ nephrologist $2 ; \mathrm{N}_{3}=$ nephrologist $3 ; \mathrm{IM}_{1}=$ internist 1 ; $\mathrm{IM}_{2}=$ internist $2 ; \mathrm{IM}_{3}=$ internist $3 ; \mathrm{AKI}=$ acute kidney injury; $\mathrm{SIADH}=$ syndrome of inappropriate antidiuretic hormone.

Table 2. Nephrologist and internist interrater agreement.

\begin{tabular}{|c|c|c|}
\hline Comparison & Kappa Coefficient (95\% Confidence Interval CI) & Agreement \\
\hline \multicolumn{3}{|l|}{ Nephrologists } \\
\hline $\mathrm{N}_{1}$ vs. $\mathrm{N}_{2}$ & $0.45(0.30,0.60)$ & Moderate \\
\hline $\mathrm{N}_{1}$ vs. $\mathrm{N}_{3}$ & $0.55(0.40,0.71)$ & Moderate \\
\hline $\mathrm{N}_{2}$ vs. $\mathrm{N}_{3}$ & $0.32(0.16,0.49)$ & Fair \\
\hline $\mathrm{N}_{1}$ vs. $\mathrm{N}_{2}$ vs. $\mathrm{N}_{3}$ & $0.43(0.34,0.53)$ & Moderate \\
\hline \multicolumn{3}{|l|}{ Internists } \\
\hline $\mathrm{IM}_{1}$ vs. $\mathrm{IM}_{2}$ & $0.47(0.31,0.63)$ & Moderate \\
\hline $\mathrm{IM}_{1}$ vs. $\mathrm{IM}_{3}$ & $0.33(0.19,0.48)$ & Fair \\
\hline $\mathrm{IM}_{2}$ vs. $\mathrm{IM}_{3}$ & $0.37(0.22,0.53)$ & Fair \\
\hline $\mathrm{IM}_{1}$ vs. $\mathrm{IM}_{2}$ vs. $\mathrm{IM}_{3}$ & $0.38(0.30,0.46)$ & Fair \\
\hline \multicolumn{3}{|l|}{ Inter-specialty } \\
\hline $\mathrm{N}_{1}$ vs. $\mathrm{IM}_{1}$ & $0.73(0.59,0.87)$ & Substantial \\
\hline $\mathrm{N}_{1}$ vs. $\mathrm{IM}_{2}$ & $0.40(0.26,0.55)$ & Fair \\
\hline $\mathrm{N}_{1}$ vs. $\mathrm{IM}_{3}$ & $0.36(0.21,0.51)$ & Fair \\
\hline $\mathrm{N}_{2}$ vs. $\mathrm{IM}_{1}$ & $0.41(0.25,0.57)$ & Moderate \\
\hline $\mathrm{N}_{2}$ vs. $\mathrm{IM}_{2}$ & $0.18(0.04,0.32)$ & Slight \\
\hline $\mathrm{N}_{2}$ vs. $\mathrm{IM}_{3}$ & $0.25(0.10,0.41)$ & Fair \\
\hline $\mathrm{N}_{3}$ vs. $\mathrm{IM}_{1}$ & $0.54(0.38,0.70)$ & Moderate \\
\hline $\mathrm{N}_{3}$ vs. $\mathrm{IM}_{2}$ & $0.31(0.16,0.47)$ & Fair \\
\hline $\mathrm{N}_{3}$ vs. $\mathrm{IM}_{3}$ & $0.27(0.10,0.43)$ & Fair \\
\hline Overall Agreement & $0.39(0.35,0.42)$ & Fair \\
\hline
\end{tabular}

Key: Kappa Coefficient Interpretation: $\leq 0$ poor; 0 - 0.02 slight; 0.21 - 0.40 fair; 0.41 - 0.60 moderate; 0.61 - 0.80 substantial; $0.81-1.0$ almost perfect. $\mathrm{N}=$ nephrologist; $\mathrm{IM}=$ internist. 
factors can be occurring simultaneously. Blood loss with resulting hypovolemia stimulates baroreceptors for AVP release. The process of surgery induces non-osmotic stimuli to AVP secretion through pro-inflammatory cytokines, positive pressure ventilation, nausea, hypoxia, hypercarbia, stress, pain and narcotics [6] [7]. In addition to AVP increasing the re-absorption of water in the collecting tubules of the nephron, limited peri-operative oral intake decreases the amount of solute needed for renal water excretion. Use of intravenous hypotonic fluids in all these situations will result in hyponatremia.

Our physician evaluators made diagnoses based on laboratory values and limited documented physical exam findings. The lab data was static, with no real time trend assessment. Oral and intravenous fluid intake was not known. Even when hyponatremia is assessed in real time, physicians struggle with defining the etiology. Clinical assessment of a patient's fluid status has a 50\% accuracy rate [8] and diagnosis of hyponatremia by experienced clinicians has a $32 \%$ accuracy rate [4].

Hypovolemia and SIADH were most commonly diagnosed by our evaluators. Hyponatremia due to hypovolemia requires $0.9 \%$ saline infusion. However, infusing $0.9 \%$ saline in hyponatremia due to SIADH will cause further decline of the serum $\mathrm{Na}$ and worsen the hyponatremia. Rather, SIADH requires free water restriction. Laboratory values can assist in differentiating between the two. In contrast to SIADH, hyponatremia tends to have urine $\mathrm{Na}<20 \mathrm{mmol} / \mathrm{L}, \mathrm{FENa}^{+}<1 \%$, uric acid $>4 \mathrm{mg} / \mathrm{dL}$ [9] and a FEurea $<12 \%$ [10]. But, because multiple mechanisms of hyponataremia may be occurring simultaneously in the post-operative state, laboratory values are not always so definitive. Measuring the rise or fall in serum $\mathrm{Na}$ after infusing $1-2 \mathrm{~L}$ of $0.9 \%$ saline can help differentiate the diagnoses. Measuring urine electrolytes prior to the infusion can help in predicting response. A urine $\mathrm{Na} \leq 50$ [11] or a urine $\mathrm{Na}+\mathrm{K} /$ plasma $\mathrm{Na}<0.5$ [12] are more indicative of hypovolemic hyponatremia and suggest that serum $\mathrm{Na}$ will increase after the infusion of 1 - 2 litres of $0.9 \%$ saline. In SIADH, the serum Na will decrease further after infusion of $0.9 \%$ saline, especially if the osmolality of the administered fluid is less than the urine osmolality [12].

\section{Conclusion}

The two most frequent causes of orthopedic post-operative hyponatremia are hypovolemia and SIADH. It is important to differentiate between these two, since hypovolemic hyponatremia requires $0.9 \%$ saline resuscitation and SIADH hyponatremia requires fluid restriction. In both cases hypotonic fluids will lower plasma $\mathrm{Na}$ and should be avoided. Making the correct diagnosis can be difficult for both internists as well as nephrologists.

\section{References}

[1] Hennrikus, E., Ou, G., Kinney, B., Lehman, E., Grunfeld, R., Wieler, J., Damluji, A., Davis III, C. and Mets, B. (2015) Prevalence, Timing, Causes, and Outcomes of Hyponatremia in Hospitalized Orthopaedic Surgery Patients. The Journal of Bone \& Joint Surgery (American), 97, 1824-1832. http://dx.doi.org/10.2106/JBJS.O.00103

[2] Waikar, S.S., Mount, D.B. and Curhan, G.C. (2009) Mortality after Hospitalization with 
Mild, Moderate, and Severe Hyponatremia. American Journal of Medicine, 122, 857-865. http://dx.doi.org/10.1016/j.amjmed.2009.01.027

[3] Callewart, C.C., Minchew, J.T., Kanim, L.E., Tsai, Y.C., Salehmoghaddam, S., Dawson, E.G. and Delamarter, R.B. (1994) Hyponatremia and Syndrome of Inappropriate Antidiuretic Hormone Secretion in Adult Spinal Surgery. Spine, 19, 1674-1679. http://dx.doi.org/10.1097/00007632-199408000-00004

[4] Fenske, W., Maier, S.K., Blechschmidt, A., et al. (2010) Utility and Limitations of the Traditional Diagnostic Approach to Hyponatremia: A Diagnostic Study. American Journal of Medicine, 123, 652-657. http://dx.doi.org/10.1016/j.amjmed.2010.01.013

[5] Spasovski, G., Vanholder, R., Allolio, B., Annane, D., Ball, S., Bichet, D., Decaux, G., Fenske, W., Hoorn, E., Ichai, C., Joannidis, M., Soupart, A., Zietse, R., Haller, M., Van der Veer, S., Van Biesen, W. and Nagler, E. (2014) Clinical Practice Guideline on Diagnosis and Treatment of Hyponatraemia. European Journal of Endocrinology, 107, G1-G47. http://dx.doi.org/10.2478/bj-2014-0014

[6] Park, S.J. and Shin, J.L. (2013) Inflammation and Hyponatremia: An Underrecognized Condition? Korean Journal of Pediatrics, 56, 519-522.

http://dx.doi.org/10.3345/kjp.2013.56.12.519

[7] Robertson, G.L. (2001) Antidiuretic Hormone. Normal and Disordered Function. Endocrinology and Metabolism Clinics of North America, 30, 671-694. http://dx.doi.org/10.1016/S0889-8529(05)70207-3

[8] Chung, H.M., Kluge, R., Schrier, R.W. and Anderson, R.J. (1987) Clinical Assessment of Extrcellular Fluid Volume in Hyponatremia. American Journal of Medicine, 83, 905-908. http://dx.doi.org/10.1016/0002-9343(87)90649-8

[9] Milionis, H.F., Liamis, G.L. and Elisaf, M.S. (2002) The Hyponatremic Patient: A Systematic Approach to Laboratory Diagnosis. CMAJ, 166, 1056-1062.

[10] Fenske, W., Stork, S. and Koschker, A.C. (2008) Value of Fractional Uric Acid Excretion in Differential Diagnosis of Hyponatremic Patients on Diuretics. The Journal of Clinical Endocrinology \& Metabolism, 93, 2991-2997. http://dx.doi.org/10.1210/jc.2008-0330

[11] Hato, T. and Ng, R. (2010) Diagnostic Value of Urine Sodium Concentration in Hyponatremia due to Syndrome of Inappropriate Antidiuretic Hormone Secretion versus Hypovolemia. Hawaii Medical Journal, 69, 264-267.

[12] Palmer, B.F. (2010) Diagnostic Approach and Management of Inpatient Hyponatremia. $J H M$, 5, S1-S7. http://dx.doi.org/10.1002/jhm.702 
Submit or recommend next manuscript to SCIRP and we will provide best service for you:

Accepting pre-submission inquiries through Email, Facebook, LinkedIn, Twitter, etc. A wide selection of journals (inclusive of 9 subjects, more than 200 journals)

Providing 24-hour high-quality service

User-friendly online submission system

Fair and swift peer-review system

Efficient typesetting and proofreading procedure

Display of the result of downloads and visits, as well as the number of cited articles

Maximum dissemination of your research work

Submit your manuscript at: http://papersubmission.scirp.org/

Or contactijcm@scirp.org 